\title{
Use of the SF-36 quality of life scale to assess the effect of pelvic floor muscle exercise on aging males who received transurethral prostate surgery
}

\author{
This article was published in the following Dove Press journal: \\ Clinical Interventions in Aging \\ 6 June 2013 \\ Number of times this article has been viewed
}

\section{Chen-Pang Hou ${ }^{1, *}$ \\ Tzu-Yu Chen ${ }^{2, *}$ \\ Chia-Chi Chang ${ }^{3}$ \\ Yu-Hsiang Lin' \\ Phei-Lang Chang' \\ Chien-Lun Chen' \\ Yu-Chao Hsu' \\ Ke-Hung Tsui' \\ 'Department of Urology, Chang Gung Memorial Hospital Linko, Chang Gung University, Taiwan, Republic of China; \\ ${ }^{2}$ Department of Nursing, Chang Gung Memorial Hospital, Taipei, Republic of China; ${ }^{3}$ College of Nursing, Taipei Medical University, Taipei, Republic of China}

*These authors contributed equally to this work
Correspondence: Ke-Hung Tsui Department of Urology, Chang Gung Memory Hospital, Chang Gung University, \#5 Fu-Shing Street Kwei-Shan,

Tao-Yuan 333, Taiwan, Republic of China

Tel +886 $3328 \quad 1200$ ext 2/37

Fax +8862 27358775

Email khtsui@yahoo.com

Yu-Chao Hsu

Department of Urology, Chang Gung

Memory Hospital, Chang Gung University, \#5 Fu-Shing Street Kwei-Shan,

Tao-Yuan 333, Taiwan, Republic of China

Tel +886 3328 I200 ext 2 I37

Fax +886227358775

Email Hsuyc@adm.cgmh.org.tw
Purpose: We used the Short Form (SF)-36 ${ }^{\circledR}$ Health Survey scale to assess the effect of pelvic floor muscle exercise (PFE) on aging males who received transurethral resection of the prostate (TUR-P).

Methods: From April 2010 to December 2010, a total of 66 patients who underwent TUR-P were enrolled in this study. They were randomized into two groups (with 33 patients in each group) - an experimental group who performed postoperative PFE every day and a control group. Data, including the International Prostate Symptom Score (IPSS), uroflowmetry study, and the SF-36 quality of life measure, were collected before the operation, and at 1, 4, 8, and 12 weeks after the operation. We analyzed the differences between the two groups with respect to their IPSS scores, maximal urinary flow rate, residual urine amount, and life quality.

Results: A total of 61 patients (experimental group: 32 patients, and control group: 29 patients) completed this study. We found that at 12 weeks postop, patients who performed PFE every day had a better maximal urinary flow rate $(16.41 \pm 6.20 \mathrm{vs} 12.41 \pm 7.28 \mathrm{~mL} / \mathrm{min})(P=0.026)$ compared with patients in the control group. The experimental group had a much greater decrease in IPSS score $(P<0.001)$. As for the SF-36 scale, the experimental group had higher scores than did the control group on both the physiological domain (54.86 vs 49.86) $(P=0.029)$ and the psychological domain (61.88 vs 52.69) $(P=0.005)$. However, there were no significant differences with respect to the postvoiding residual urine between the two groups $(57.24 \pm 52.95$ vs $64.68 \pm 50.63 \mathrm{~mL})(P=0.618)$.

Conclusion: Compared with the control group, patients who performed PFE for 12 weeks after TUR-P showed improvement in their maximal urinary flow rate and lower urinary tract symptoms, and had a better quality of life. The immediate initiation of PFE is suggested for patients who undergo TUR-P.

Keywords: benign prostatic hyperplasia, SF-36, pelvic floor exercise, prostatectomy, quality of life

\section{Introduction}

Benign prostatic hyperplasia (BPH) is a major cause of urinary tract symptoms in the aging male. Globally, it affects about 210 million males. ${ }^{1}$ While the prevalence rate of symptomatic BPH is $2.7 \%$ for men aged $45-49$, this increases to $24 \%$ by the age of 80 years. For a symptom-free man of 46 years, the risk of developing symptomatic BPH over the next 30 years is $45 \% .^{1}$ Transurethral resection of the prostate (TUR-P) has been the gold standard of surgical treatment for patients with obstructing BPH. ${ }^{2,3}$ How- 
ever, many transient bladder dysfunction symptoms, such as terminal dribbling, urinary frequency, and incontinence are common occurrences after surgery, in the aging male. More and more evidence reveal that pelvic floor exercise (PFE), which has been used in treating female stress incontinence, may be helpful in reducing transient bladder dysfunction symptoms. However, not many studies have focused on how post-TUR-P PFE influences patients' quality of life. Recently, the Medical Outcome Study Short Form (SF)-36 ${ }^{\circledR}$ Health Survey (QualityMetric Inc, Lincoln, RI, USA) has been used in the measurement of generic health status in a number of medical studies. ${ }^{4}$ We used the SF-36 to evaluate the patient's quality of life in our study. The SF-36 was devised by Dr John Ware Jr, in 1990, as a multipurpose, short health survey consisting of only 36 questions and requiring 5 to 10 minutes to complete. The SF-36 measures eight dimensions of the interviewees' physical and mental states. The eight scales measure: physical functioning (ten questions), role limitation due to physical problems (four questions), body pain (two questions), general health (five questions), vitality (four questions), social functioning (two questions), role limitation due to emotional problems (three questions), and mental health (five questions). There is also an additional self-evaluation form used by the interviewees to report the health condition. Each scale score ranges from 0 to 100 , with a higher score indicating a better level of quality of life. ${ }^{4}$

PFE, more commonly called the Kegel exercise, was first described in 1948 by Dr Arnold Kegel. ${ }^{5}$ It is performed by repeatedly contracting and relaxing the pubococcygeus muscles of the pelvic floor. For women, the exercise is usually done to reduce the symptoms of stress urinary incontinence. ${ }^{6}$ It also provides a good response in the treatment and the prevention of vaginal and uterine prolapse. ${ }^{7}$ For men, PFE is an effective treatment for terminal dribbling. ${ }^{8}$ It seems helpful in reducing the frequency of urination and improving the symptoms of urge incontinence in men, within the first 4 weeks after transurethral prostatectomy. ${ }^{9}$ The study of Zhang et al showed that compared with the control group, patients undergoing radical prostatectomy followed by a 3-month-long PFE regime had less incontinence problems as well as better self-confidence, especially in their marital relationship and social outings. ${ }^{10} \mathrm{~A}$ prospective study design was undertaken to evaluate the hypothesis that PFE can enhance the early recovery and early bladder function recovery after TUR-P. The study used the SF-36 quality of life scale, as it was judged to be an effective and useful functional score in the investigation of BPH treatment.

\section{Material and methods}

From April 26 to December 31, 2010, a total of 66 patients who were diagnosed with benign prostate hyperplasia and underwent TUR-P were enrolled in this study. These patients had the same indications of operation, and were admitted only through our urologic outpatient department. The inclusion criteria were: age between 60 to 90 years; remarkable lower urinary tract symptoms (LUTS) with poor response to medication; ambulatory; and able to communicate verbally. The exclusion criteria were: indwelling Foley catheter-dependent postdischarge; neurogenic bladder; dementia or any disability interfering with verbal communication.

The 66 patients were randomly classified into either the experimental group (group 1: 33 patients) or the control group (group 2: 33 patients). The patients' baseline data, including age, sexual activity, International Prostate Symptom Score (IPSS score), ${ }^{11}$ SF-36 questionnaire, and their educational level, were recorded. The ASA (American Society of Anesthesiologists) score was also recorded. This score was first suggested in 1940 by a committee of American Society of Anesthesiologists, and was designed to standardize the physical status of the patient who was going to undertake the anesthesia. ${ }^{12}$ Uroflowmetry and a bladder scan for residual urine were performed on every patient before the operation. Urinary catheterization, for drainage, was performed on all patients after the TUR-P, and the catheter was removed 2 days postoperatively if no remarkable complication occurred. The patients in group 1 were asked to start the PFE after the removal of the Foley catheter. After receiving instructions regarding basic anatomy and the physiology of micturition, the group 1 patients were taught to tighten and lift their pelvic floor muscles as if interrupting the flow of urine during voiding. The patients were instructed to contract pelvic muscles for 5 seconds and then to relax them for 10 seconds. A surface electromyogram (EMG) was applied to confirm the correct pelvic wall exercise of the patients. The training sessions were completed only when the patients were familiar with the exercise programs and when the EMG showed an adequate pelvic wall contraction without simultaneous tightening of the abdominal muscles. After the group 1 patients were discharged from the hospital, they were asked to practice 5 minutes per single PFE, three times a day. These patients received telephone interviews at least once a week, reminding them to perform the exercise and answering any questions they might have about the exercise.

All patients were asked to return to our outpatient service to reevaluate their IPSS scores at 1, 4, and 8 weeks 
post-TUR-P. At 12 weeks postop, their IPSS scores, SF-36 questionnaire (to evaluate the patients' quality of life), maximal urinary flow rates (Qmax), voiding volume (VV), and postvoiding residual urine amount (PVR) were reevaluated.

We used SPSS 15.0 (SPSS, Inc, Chicago, IL, USA) for statistical analysis. The Chi-squared test was used to compare the patient demographics of the two groups. The Mann-Whitney U test was used to compare the changes in IPSS scores, SF-36 scores, and PVR between the two groups. All statistical tests were conducted with a significance level of 0.05 .

\section{Results}

Among the 66 patients who were enrolled in this study, two patients were unable to have their urinary catheter removed (due to poor voiding) before discharge from the hospital. Three patients were lost to follow-up during the study period. Therefore, there were a total of 61 patients (group 1: 32 patients; group 2: 29 patients) who completed this study. The patient demographics are shown in Table 1. There were no significant differences between the two groups with respect to age, sexual activity, ASA scores, or educational status.

Prior to discharge from the hospital, three patients in group 1 and five patients in group 2 complained of mild urge incontinence, and all recovered within 4 weeks. No patients mentioned symptoms of stress incontinence. Figure 1 shows the IPSS scores of the two groups before and 12 weeks after the surgery. Figure 2 shows the IPSS changes with time, for the two groups. It is evident that the two groups had similar severity of LUTS $(22.09 \pm 6.64$ vs $21.40 \pm 6.02)(P=0.609)$

Table I Patient demographics

\begin{tabular}{|c|c|c|c|}
\hline & $\begin{array}{l}\text { Group I } \\
(n=32) \\
N(\%)\end{array}$ & $\begin{array}{l}\text { Group } 2 \\
(n=29) \\
N(\%)\end{array}$ & $P$-value* \\
\hline Age & $69.67 \pm 6.09$ & $71.41 \pm 6.67$ & 0.715 \\
\hline \multicolumn{4}{|l|}{ Sexual activity } \\
\hline Yes & $17(53.1)$ & $16(55.2)$ & 0.873 \\
\hline No & $15(46.9)$ & $13(44.8)$ & \\
\hline \multicolumn{4}{|l|}{ ASA score } \\
\hline I & $2(6.2)$ & $2(6.9)$ & 0.915 \\
\hline ॥ & $19(59.4)$ & $19(65.5)$ & \\
\hline III & II (34.4) & $8(27.6)$ & \\
\hline \multicolumn{4}{|l|}{ Education status } \\
\hline No & I (3.I) & $4(13.8)$ & 0.206 \\
\hline Elementary school & $20(62.5)$ & $19(65.5)$ & \\
\hline High school or higher & II (34.4) & $6(20.7)$ & \\
\hline
\end{tabular}

Note: *Chi-squared test.

Abbreviation: ASA, American Society of Anesthesiologists. before the TUR-P. However, at 12 weeks after the operation, the group 1 patients who practiced PFE had less severe LUTS compared with patients in the control group $(3.32 \pm 0.84 \mathrm{vs}$ $6.33 \pm 1.77)(P<0.001)$. There were no significant differences with regards to voiding symptom scores $(1.38 \pm 0.95$ vs $1.53 \pm 0.82)(P=0.511)$, but significant differences on the storage (urgency, frequency, and nocturia) symptom scores $(1.94 \pm 1.21$ vs $4.81 \pm 1.85)(P<0.001)$. Before the operation, as shown in Table 2, patients in the two groups had similar Qmax $(7.90 \pm 4.63 \mathrm{~mL} / \mathrm{s}$ vs $8.45 \pm 4.82 \mathrm{~mL} / \mathrm{s})(P=0.554)$ and VV $(175.34 \pm 85.22 \mathrm{~mL}$ vs $189.09 \pm 83.58 \mathrm{~mL})$ $(P=0.461)$. However, the group 1 patients, who had the PFE, had a significantly better Qmax at postoperative week 12 $(16.41 \pm 6.20 \mathrm{~mL} / \mathrm{s}$ vs $12.41 \pm 7.28 \mathrm{~mL} / \mathrm{s})(P=0.026)$ Group 1 patients had a slightly higher VV at postoperative week 12 compared with group 2 patients $(269.56 \pm 69.97 \mathrm{~mL}$ vs $237.58 \pm 51.81 \mathrm{~mL}$ ); however, this was not a statistically significant difference $(P=0.097)$. Regarding patient's PVR, there were no significant differences between the two groups either before $(151.91 \pm 111.36$ vs $169.41 \pm 240.83 \mathrm{~mL})$ $(P=0.133)$ or at 12 weeks after the operation $(57.24 \pm 52.95$ vs $64.68 \pm 50.63 \mathrm{~mL})(P=0.618)$.

Table 3 shows that the two groups had similar status quality of life scores before surgery, on both the physical domains $(48.50 \pm 8.95$ vs $47.14 \pm 1.17)(P=0.656)$ and mental health domains $(48.68 \pm 12.78$ vs $47.15 \pm 16.07)(P=0.991)$. Table 4 showed that group 1 patients had better quality of life at 12 weeks after surgery, on both the physical domains $(54.86 \pm 8.62$ vs $49.86 \pm 11.23)(P=0.029)$ and the mental health domains $(56.21 \pm 6.20$ vs $48.52 \pm 11.94)(P=0.005)$. When items of the physical domains were analyzed further, the group 1 patients had higher scores on general health $(P=0.005)$, but there were no significant differences with respect to physical functioning, body pain, or physical role limitations. When items of the mental health domains were analyzed further, the group 1 patients had higher scores on all the items, including role limitation, vitality, mental health, and social functioning.

\section{Discussion}

PFE is most effective with specific instructions and when monitored by health professionals. The effectiveness of PFE is further strengthened if it is performed by motivated patients. ${ }^{13}$ Therefore, there were special technicians who taught the patients about the correct pelvic floor contraction in our study. With the aids of the surface EMG, we were able to confirm that the patients were performing the pelvic wall exercise in the correct way. The patients also received 


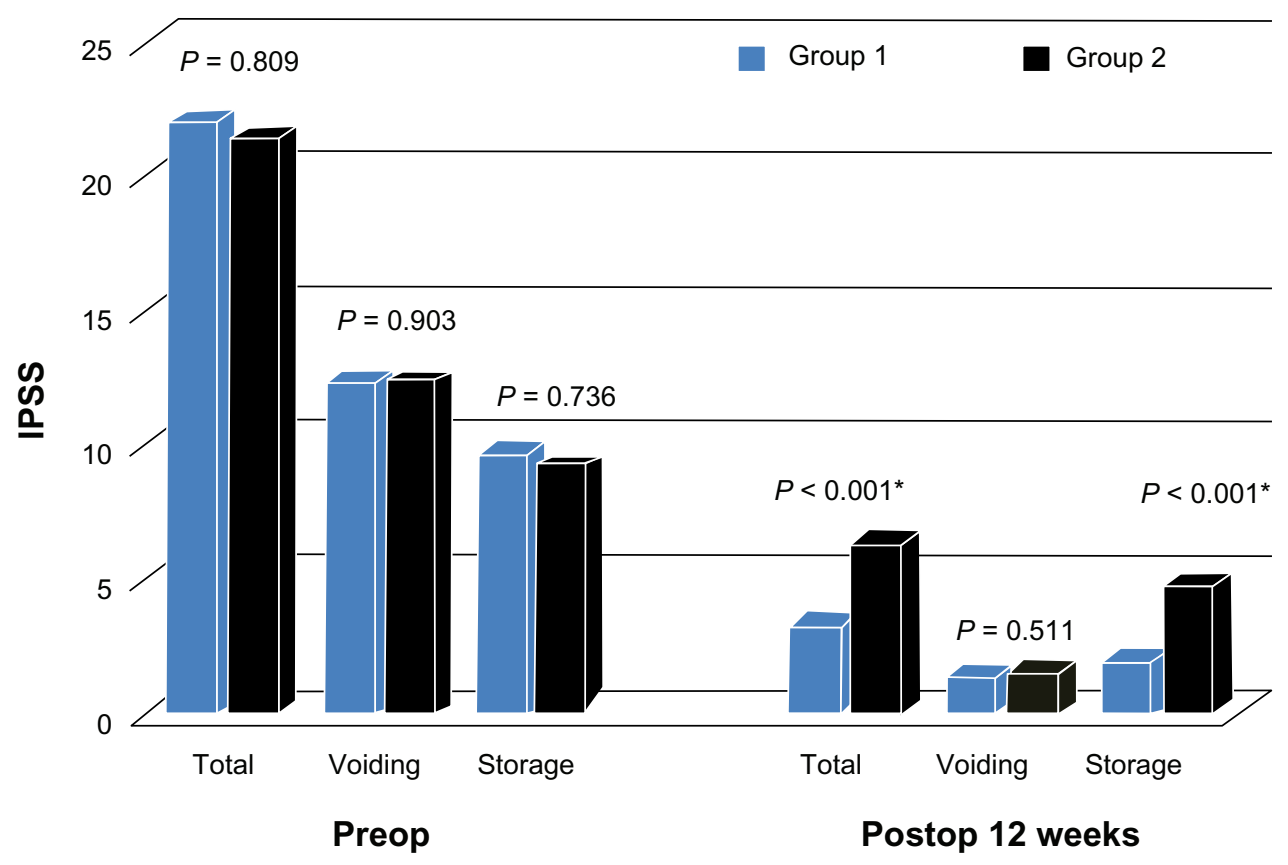

Figure I IPSS scores of the two groups before and 12 weeks after the surgery.

Notes: *Mann-Whitney $U$ test.

Abbreviation: IPSS, International Prostate Symptom Score.

telephone interviews at least once a week to remind them to perform the exercise therapy. In addition, the interviewer would also answer any queries that the patients had about the exercise. Since there were no significant differences in the patients demographics, as shown in Table 1, the patients were all equally capable of learning and following the pelvic muscle exercise regime. As shown in Figure 1, the patients in the control group and the experimental group had no significant differences in their IPSS scores at the beginning.
Namely, patients of the two groups had a similar severity of LUTS before the operation. Most of the studies described earlier indicated that PFE was able to reduce the symptoms of urgency, frequency, postmicturition dribble, and stress incontinence after the prostate surgery. ${ }^{14,15}$ The study by Chang et al revealed that patients who performed PFE for 4 weeks after TUR-P were able to increase the length of between-voiding intervals, from about 30 minutes to longer than 2 hours. ${ }^{9}$ However, very few studies have mentioned the

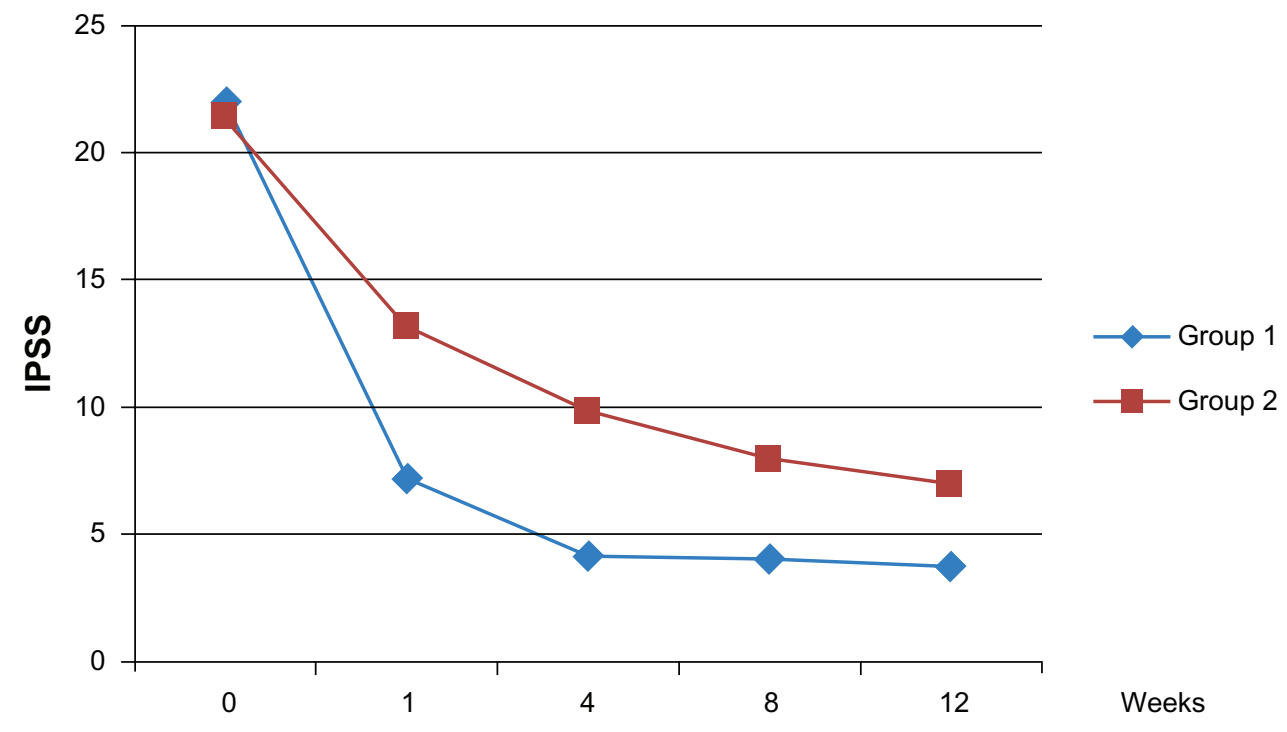

Figure 2 The IPSS changes over time, in the two groups. Abbreviation: IPSS, International Prostate Symptom Score. 
Table 2 Qmax and PVR of the 2 groups before and 12 weeks after operation

\begin{tabular}{lccl}
\hline & $\begin{array}{l}\text { Group I } \\
\text { M } \pm \text { SD }\end{array}$ & $\begin{array}{l}\text { Group 2 } \\
\text { M } \pm \text { SD }\end{array}$ & P-value* \\
\hline Qmax (mL/s) & & & \\
$\quad$ Before operation & $7.90 \pm 4.63$ & $8.45 \pm 4.82$ & 0.554 \\
$\quad \begin{array}{l}\text { Postop I2 weeks } \\
16.41 \pm 6.20\end{array}$ & $12.41 \pm 7.28$ & $0.026^{*}$ \\
VV (mL) & & & \\
$\quad$ Before operation & $175.34 \pm 85.22$ & $189.09 \pm 83.58$ & 0.461 \\
$\quad \begin{array}{l}\text { Postop I2 week } \\
\text { PVR (mL) }\end{array}$ & $269.56 \pm 69.97$ & $237.58 \pm 51.81$ & 0.097 \\
$\quad$ Before operation & $151.91 \pm 111.36$ & $169.41 \pm 240.83$ & 0.133 \\
$\quad$ Postop 12 weeks & $57.24 \pm 52.95$ & $64.68 \pm 50.63$ & 0.618 \\
\hline
\end{tabular}

Note: *Mann-Whitney $U$ test.

Abbreviations: PVR, postvoiding residual urine; Qmax, maximal flow rate; $\mathrm{SD}$, standard deviation; $\mathrm{VV}$, voiding volume.

influence of PFE on the Qmax. Our study showed that patients who had 12 weeks of PFE had a better Qmax compared with the control group, as shown in Table 2. The possible reason might be that repeated pelvic floor muscle training was able to increase the muscle mass, close the levator hiatus, shorten muscle length, elevate the resting position of the bladder and rectum, and provide a better pelvic muscle relaxation during the voiding phase of micturition. ${ }^{16}$ As for VV and PVR, the patients in both groups had significant improvement after TUR-P; there were no significant differences between the two groups with respect to their VV and PVR, 12 weeks after the operation.

Figure 2 shows changes of the IPSS scores over time for the two groups. We found that group 1 patients had lower IPSS scores from the first postop week to the 12th postop week. At 12 weeks postop, as shown in Figure 1, group 1 patients had significantly lower scores on the storage symptoms, but no differences were observed in group 2 patients with respect to their voiding symptoms (displaying weak

Table 3 SF-36 scores before the operation

\begin{tabular}{llll}
\hline & $\begin{array}{l}\text { Group I } \\
(\mathbf{n}=\mathbf{3 2}) \\
\mathbf{M} \pm \mathbf{S D}\end{array}$ & $\begin{array}{l}\text { Group 2 } \\
(\mathbf{n}=\mathbf{2 9}) \\
\mathbf{M} \pm \mathbf{S D}\end{array}$ & $\begin{array}{l}\text { P-value* } \\
\end{array}$ \\
\hline Physical component & $48.50 \pm 8.95$ & $47.14 \pm 1.17$ & 0.656 \\
Physical functioning & $83.91 \pm 19.66$ & $84.31 \pm 19.35$ & \\
Body pain & $89.22 \pm 16.67$ & $81.69 \pm 29.06$ & \\
General health & $63.47 \pm 20.11$ & $59.92 \pm 24.13$ & \\
Physical role limitation & $42.97 \pm 41.24$ & $43.10 \pm 41.67$ & \\
Mental health component & $48.68 \pm 12.78$ & $47.15 \pm 16.07$ & 0.991 \\
Mental role limitation & $67.71 \pm 43.57$ & $67.82 \pm 42.24$ & \\
Vitality & $63.13 \pm 23.99$ & $58.97 \pm 27.43$ & \\
Mental health & $71.38 \pm 18.23$ & $68.55 \pm 22.87$ & \\
Social functioning & $65.23 \pm 30.57$ & $63.79 \pm 34.93$ & \\
\hline
\end{tabular}

Note: *Mann-Whitney $U$ test.

Abbreviation: SD, standard deviation.
Table 4 SF-36 scores of the two groups 12 weeks after operation

\begin{tabular}{llll}
\hline & $\begin{array}{l}\text { Group I } \\
(\mathbf{n}=\mathbf{3 2}) \\
\mathbf{M} \pm \mathbf{~ S D}\end{array}$ & $\begin{array}{l}\text { Group 2 } \\
\mathbf{( n = 2 9 )} \\
\mathbf{M} \pm \mathbf{~ S D ~}\end{array}$ & P-value $^{\S}$ \\
\hline Physical component & $54.86 \pm 8.62$ & $49.86 \pm 11.23$ & $0.029^{*}$ \\
Physical functioning & $89.69 \pm 17.13$ & $85.82 \pm 21.60$ & 0.222 \\
Body pain & $93.66 \pm 15.16$ & $89.48 \pm 22.7 \mathrm{I}$ & 0.621 \\
General health & $82.03 \pm 14.05$ & $64.93 \pm 27.16$ & $0.005^{*}$ \\
Physical role limitation & $68.75 \pm 36.48$ & $51.72 \pm 38.92$ & 0.092 \\
Mental health component & $56.21 \pm 6.20$ & $48.52 \pm 11.94$ & $0.005^{*}$ \\
Mental role limitation & $93.75 \pm 21.48$ & $73.81 \pm 37.80$ & $0.026^{*}$ \\
Vitality & $80.47 \pm 13.16$ & $64.14 \pm 24.02$ & $0.016^{*}$ \\
Mental health & $88.00 \pm 10.5 \mathrm{I}$ & $77.38 \pm 18.68$ & $0.028^{*}$ \\
Social functioning & $90.63 \pm 14.20$ & $76.29 \pm 29.57$ & $0.013^{*}$ \\
\hline
\end{tabular}

Note: $\$$ Mann-Whitney $U$ test. *significant difference.

Abbreviation: SD, standard deviation.

stream, intermittency, straining, and incomplete emptying of the bladder). According to our data, it appeared that PFE was more effective in improving the patients' storage symptoms. This finding is compatible with the study of Porru et al, which revealed that instead of relying on surgery alone, PFE produces a quicker improvement in the patients' urinary symptoms after TUR-P, especially with regard to their urge incontinence and voiding interval. ${ }^{17}$ The reason why PFE is able to relieve storage symptoms might be that it is capable of inhibiting detrusor muscle spasm by voluntary contraction of the pelvic floor muscle at the time of the urge to void. It also prevents sudden falls in urethral pressure due to a change in pelvic floor muscle morphology, position, and neuromuscular function. ${ }^{18}$ Repeated contraction of the pubococcygeus muscles, puborectalis muscles, and the external urethral sphincter supposedly prevents the internal sphincter relaxation induced by the micturition reflex, with a resulting detrusor relaxation and suppression of involuntary voiding. ${ }^{19}$

The reason that the SF-36 was used to evaluate patient quality of life in this study was that it is a very simple measurement, which takes only 10 minutes to complete. In addition, it is also a highly reliable measure and has been translated into numerous different language versions. ${ }^{20}$ In our study, the Chinese version of the SF-36 questionnaire, translated, adapted and validated by $\mathrm{Lu}$ et $\mathrm{al}^{21}$ was used. The relationships between LUTS and the quality of life have been previously reported in the literature. Tubaro and $\mathrm{La}$ Vecchia found that the severity of LUTS strongly influences patients' quality of life. ${ }^{22}$ Although patients with mild LUTS can usually continue their normal life, patients with more severe symptoms are often bothered by those symptoms. This is because their daily activities are often affected by these symptoms, which consequently reduces their quality of 
life. Our study revealed that not only was postoperative PFE able to reduce the severity of LUTS, it was also capable of improving patients' quality of life compared with the control group. The PFE was helpful in relieving the postoperative storage symptoms. Previous studies have demonstrated that bladder irritative symptoms have a negative impact on the subjective health-related quality of life and that the improvement of these symptoms correlated with improvements in patients' perception of their bladder-related problems as well as their health-related quality of life. ${ }^{23-25}$ In our study, the experimental group only had slightly higher scores on the physical component $(P=0.029)$. In addition, for the physical component items, there were no significant differences between the two groups, apart from the item of general health. On the contrary, the experimental group had significantly higher scores on the mental health component $(P=0.005)$. In addition, there were significant differences between the two groups on every item of the mental health component. This exemplified that PFE mainly affected the patients' quality of life with respect to mental health. When compared with the control group, the experimental group showed a much better result in their role limitation, vitality, mental health, and social functioning. The explanation for the above finding is that patients in both groups underwent the same type of surgical procedure and showed no significant differences in their physical well-being, their feelings of pain, and their daily routines. Therefore, the two groups showed no significant differences in the physical component of the SF-36 survey. On the contrary, patients in the experimental group had a better Qmax, greater improvement in urinary storage symptoms, longer voiding interval, better self-confidence, less difficulties in socializing, hence, a better life-quality with regard to their mental state.

As with most studies, our study had some limitations that are worth mentioning. First, we only followed our patients for 12 months. Therefore, the long-term outcome, especially the quality of life, needs to be investigated further. Second, we cannot ignore the impact of the so called "subject-expectancy effect." The patients in the experimental group were given a complete educational program on doing the Kegel exercise, postoperatively. The instructors not only gave patients detailed instructions for the exercise, but also explained the advantages of such. Patients were also encouraged to take an active role in finding out more about the advantages of doing this exercise, through books and the media. Therefore, patients were more likely to expect a much better life quality. As a result, the "subject-expectancy effect" might have caused some biases in the current study. In order to get a more subjective result, it would be necessary to devise an additional placebo exercise program.

\section{Conclusion}

Immediate initiation of PFE is suggested for the patients who undergo TUR-P. The 12-week exercise program gives the patients a better recovery from LUTS, a higher Qmax, and a better quality of life.

\section{Disclosure}

The authors report no conflicts of interest in this work.

\section{References}

1. Verhamme KM, Dieleman JP, Bleumink GS, et al. Incidence and prevalence of lower urinary tract symptoms suggestive of benign prostatic hyperplasia in primary care - the Triumph project. Eur Urol. 2002;42(4):323-328.

2. Lin YH, Chen SM, Chang PL, Chen CL, Tsui KH. The outcome of a photoselective vaporization prostatectomy using a high-performance system to treat benign prostatic hyperplasia with acute urinary retention. Urol Sci. 2011;22(4):151-153.

3. Stewart AL, Hays RD, Ware JE. The MOS short-form general health survey. Reliability and validity in a patient population. Med Care. 1988;26(7):724-735.

4. Ware JE Jr, Sherbourne CD. The MOS 36-item short-form health survey (SF-36): I. Conceptual framework and item selection. Med Care. 1992;30(6):473-483.

5. Kegel AH. The nonsurgical treatment of genital relaxation; use of the perineometer as an aid in restoring anatomic and functional structure. Ann West Med Surg. 1948;2(5):213-216.

6. Dumoulin C, Lemieux MC, Bourbonnais D, Gravel D, Bravo G, Morin M. Physiotherapy for persistent postnatal stress urinary incontinence: a randomized controlled trial. Obstet Gynecol. 2004;104(3): 504-510.

7. Hagen S, Stark D. Conservative prevention and management of pelvic organ prolapse in women [review]. Cochrane Database Syst Rev. 2011;(12):CD003882.

8. Paterson J, Pinnock CB, Marshall VR. Pelvic floor exercises as a treatment for post-micturition dribble. Br J Urol. 1997;79(6):892-897.

9. Chang PL, Tsai LH, Huang ST, Wang TM, Hsieh ML, Tsui KH. The early effect of pelvic floor muscle exercise after transurethral prostatectomy. J Urol. 1998;160(2):402-405.

10. Zhang AY, Strauss GJ, Siminoff LA. Effects of combined pelvic floor muscle exercise and a support group on urinary incontinence and quality of life of postprostatectomy patients. Oncol Nurs Forum. 2007; 34(1):47-53.

11. Barry MJ, Fowler FJ Jr, O’Leary MP, et al. The American Urological Association symptom index for benign prostatic hyperplasia. The Measurement Committee of the American Urological Association. J Urol. 1992;148(5):1549-57; discussion 1564.

12. Saklad M. Grading of patients for surgical procedures. Anesthesiology. 1941;2:281-284.

13. Meaglia JP, Joseph AC, Chang M, Schmidt JD. Post-prostatectomy urinary incontinence: response to behavioral training. $J$ Urol. 1990;144(3):674-676.

14. Glazener C, Boachie C, Buckley B, et al. Urinary incontinence in men after formal one-to-one pelvic-floor muscle training following radical prostatectomy or transurethral resection of the prostate (MAPS): two parallel randomised controlled trials. Lancet. 2011;378(9788): 328-337.

15. Sandhu JS, Eastham JA. Factors predicting early return of continence after radical prostatectomy. Curr Urol Rep. 2010;11(3):191-197. 
16. Bø K, Braekken IH, Majida M, Engh ME. Constriction of the levator hiatus during instruction of pelvic floor or transversus abdominis contraction: a 4D ultrasound study. Int Urogynecol J Pelvic Floor Dysfunct. 2009;20(1):27-32.

17. Porru D, Campus G, Caria A, et al. Impact of early pelvic floor rehabilitation after transurethral resection of the prostate. Neurourol Urodyn. 2001;20(1):53-59.

18. Jackson J, Emerson L, Johnston B, Wilson J, Morales A. Biofeedback: a noninvasive treatment for incontinence after radical prostatectomy Urol Nurs. 1996;16(2):50-54.

19. Shafik A, Shafik IA. Overactive bladder inhibition in response to pelvic floor muscle exercises. World J Urol. 2003;20(6):374-377.

20. Ware JE Jr, Kosinski M, Gandek B, et al. The factor structure of the SF-36 Health Survey in 10 countries: results from the IQOLA Project. International Quality of Life Assessment. J Clin Epidemiol. 1998;51(11):1159-1165.
21. Lu JR, Tseng HM, Tsai YJ. Assessment of health-related quality of life in Taiwan (I): development and psychometric testing of SF-36 Taiwan version. Taiwan J Public Health. 2003;22(6):501-511.

22. Tubaro A, La Vecchia C; Uroscreening Study Group. The relation of lower urinary tract symptoms with life-style factors and objective measures of benign prostatic enlargement and obstruction: an Italian survey. Eur Urol. 2004;45(6):767-772.

23. Stewart WF, Van Rooyen JB, Cundiff GW, et al. Prevalence and burden of overactive bladder in the United States. World J Urol. 2003;20(6) 327-336.

24. Coyne K, Revicki D, Hunt T, et al. Psychometric validation of an overactive bladder symptom and health-related quality of life questionnaire: the OAB-q. Qual Life Res. 2002;11(6):563-574.

25. Coyne KS, Zhou Z, Thompson C, Versi E. The impact on health-related quality of life of stress, urge and mixed urinary incontinence. BJU Int. 2003;92(7):731-735.
Clinical Interventions in Aging

\section{Publish your work in this journal}

Clinical Interventions in Aging is an international, peer-reviewed journal focusing on evidence-based reports on the value or lack thereof of treatments intended to prevent or delay the onset of maladaptive correlates of aging in human beings. This journal is indexed on PubMed Central, MedLine, the American Chemical Society's 'Chemical Abstracts Ser-

\section{Dovepress}

vice' (CAS), Scopus and the Elsevier Bibliographic databases. The manuscript management system is completely online and includes a very quick and fair peer-review system, which is all easy to use. Visit http://www.dovepress.com/testimonials.php to read real quotes from published authors. 